\title{
Secreted proteins from carotid endarterectomy: an untargeted approach to disclose molecular clues of plaque progression
}

Silvia Rocchiccioli ${ }^{1 *}$, Gualtiero Pelosi ${ }^{1}$, Silvia Rosini ${ }^{1}$, Michele Marconi ${ }^{2}$, Federica Viglione ${ }^{1}$, Lorenzo Citti ${ }^{1}$, Mauro Ferrari ${ }^{2}$, Maria Giovanna Trivella' and Antonella Cecchettini ${ }^{1,3}$

\begin{abstract}
Background: Atherosclerosis is the main cause of morbidity and mortality in Western countries and carotid plaque rupture is associated to acute events and responsible of $15-20 \%$ of all ischemic strokes. Several proteomics approaches have been up to now used to elucidate the molecular mechanisms involved in plaque formation as well as to identify markers of pathology severity for early diagnosis or target of therapy. The aim of this study was to characterize the plaque secretome. The advantage of this approach is that secretome mimics the in vivo condition and implies a reduced complexity compared to the whole tissue proteomics allowing the detection of under-represented potential biomarkers.
\end{abstract}

Methods: Secretomes from carotid endarterectomy specimens of 14 patients were analyzed by a liquid chromatography approach coupled with label free mass spectrometry. Differential expression of proteins released from plaques and from their downstream distal side segments were evaluated in each specimen. Results were validated by Western blot analysis and ELISA assays. Histology and immunohistochemistry were performed to characterize plaques and to localise the molecular factors highlighted by proteomics.

Results: A total of 463 proteins were identified and 31 proteins resulted differentially secreted from plaques and corresponding downstream segments. A clear-cut distinction in the distribution of cellular- and extracellular-derived proteins, evidently related to the higher cellularity of distal side segments, was observed along the longitudinal axis of carotid endarterectomy samples. The expressions of thrombospondin-1, vitamin D binding protein, and vinculin, as examples of extracellular and intracellular proteins, were immunohistologically compared between adjacent segments and validated by antibody assays. ELISA assays of plasma samples from 34 patients and 10 healthy volunteers confirmed a significantly higher concentration of thrombospondin-1 and vitamin D binding protein in atherosclerotic subjects.

Conclusions: Taking advantage of the optimized workflow, a detailed protein profile related to carotid plaque secretome has been produced which may assist and improve biomarker discovery of molecular factors in blood. Distinctive signatures of proteins secreted by adjacent segments of carotid plaques were evidenced and they may help discriminating markers of plaque complication from those of plaque growth.

Keywords: Atherosclerosis, Carotid plaques, Proteomics, Secretome

\footnotetext{
* Correspondence: silvia.rocchiccioli@ifc.cnr.it

${ }^{1}$ National Research Council, Institute of Clinical Physiology, Via Moruzzi, Pisa, Italy

Full list of author information is available at the end of the article
} 


\section{Background}

Atherosclerosis is a chronic immune-inflammatory disease of the wall of medium- and large-sized arteries and it is the main cause of morbidity and mortality in Western countries due to acute cardiovascular events secondary to partial or total thrombotic obstruction of vessel lumen $[1,2]$. Rupture of carotid atherosclerotic plaques leads to atherothrombosis that accounts for approximately $20 \%$ of all strokes, a leading cause of disability, and the third most common cause of death [3].

Recently, a great interest has been focused on the identification of tissue markers of atherosclerosis, at genomics, transcriptomics [4] or proteomics levels. The majority of proteomics studies were performed on plaque extracts analyzed by two-dimensional electrophoresis followed by MALDI TOF mass spectrometry $[5,6]$, but, with this approach, mainly constitutive proteins are identified and potential, usually low-expressed biomarkers may not be detected. To overcome these limitations, Olson et al. [7] applied two-dimensional differential gel electrophoresis (2D-DIGE) in combination with tandem mass spectrometry (MS/MS) to compare protein distribution in an intra-individual study of severely atherosclerotic segments of internal carotid artery compared to partially preserved segments. In this way, they identified 19 proteins with a differential distribution along the artery. Another interesting approach was exploited by Martinet et al. [8] who screened human carotid endarterectomy (CEA) specimens using 823 monoclonal antibodies with Western array technology and were able to identify 7 differentially expressed proteins. The potential use of tissue proteomics as a tool for clinically useful biomarker discovery has been recently prospected by de Kleijn et al. [9] who found that osteopontin expression in carotid plaques and in blood is predictive for atherothrombotic events but it does not correlate with vulnerability features.

An alternative proteomics approach consists of the analysis of proteins secreted by explanted arteries and was first suggested by Duran et al. [10]. The great advantage of tissue secretome studies is that secretome mimics the in vivo condition and implies a reduced complexity compared to serum/plasma or entire tissue proteomics as well as a much narrower protein dynamic range, thus allowing the detection of under-represented potential biomarkers.

In fact, in biomarker discovery, plasma represents the sample of choice since it shows traces of all biological events and, moreover, it can be easily and non-invasively collected. On the contrary, in proteomics studies, plasma proteome is hampered by major limits such as the high dynamic range of plasma proteins and a great biological variability. For all these reasons, the analysis of proteins that are secreted by tissues into circulation has attained interest for discovery of novel biomarkers and it represents a way to gain knowledge of biological mechanisms [10,11].

An optimal culture set-up of arterial secretome in order to reduce plasma contamination and detect low abundance proteins is a recent achievement [12]. Also recently, secretomes from thromboendartectomy specimens were exploited to select nine secretome-specific antibodies that allowed the immuno-purification and successive identification of 22 proteins. Among them, junction plakoglobin has been suggested as a potential biomarker of atherosclerosis [13].

A main issue in molecular studies of vascular pathology is the cellular and extracellular heterogeneity of the plaque and of the adjacent wall where multiple components (calcium, lipids, collagens and others) and cell types (vascular smooth muscle cells (VSMCs), endothelial cells (EC), macrophages and other inflammatory cells) are present, all contributing to plaque progression and/or complication.

Several previous and recent papers have highlighted a close link between the longitudinal distribution of mechanical forces (flow shear stress and plaque wall stress) and corresponding morphological features (cell distribution and type) along plaque and its distal side [14-18]. In particular, the low flow shear stress in downstream side is associated to atherosclerosis progression with increased VSMCs and macrophages, whereas the high plaque wall stress in the upstream area is associated to cap rupture of vulnerable lesions and increased expression of proteolysis and apoptosis markers [14]. These reports support the opinion that carotid plaque and its corresponding adjacent distal side may retain distinctive protein signatures: therefore, differential expression of proteins released by plaque-containing upstream segment (P) and by its downstream distal side (DS) segment has been evaluated in each CEA specimen.

Aims of the study were: (a) to characterize the overall atherosclerotic carotid secretion with an untargeted approach able to reconstruct a complete protein map; (b) to evaluate the differences in secretomes from central plaque and corresponding distal side segments, as putative areas of plaque complication and stable growth respectively; (c) to conduct a secretome-assisted plasma analysis of some differentially expressed proteins to be exploited as markers of disease for non-invasive risk assessment.

Secretomes were analyzed by a liquid chromatography approach coupled with mass spectrometry (LC-MS/MS). Label-free MS/MS based quantification was performed and validated by Western blot analysis and ELISA assay. Histology and immunohistochemistry were performed to characterise CEA specimens and to localize the molecular factors highlighted by proteomics. ELISA assays of 
thrombospondin-1 and vitamin D binding protein were performed in plasma samples of 34 CEA candidates and 10 healthy controls.

\section{Methods}

\section{Ethics statement}

Clinical data were derived from medical records, following data security guidelines and declaration of Helsinki. All subjects gave written informed consent to participate to the study in accordance with the Ethics Committee requirements. The ethical approval for this study was granted by Ethics Commission (Clinical Trials Ethics Commission) of Pisa University Hospital.

\section{Patient clinical characterization}

Human internal carotid artery (ICA) specimens and pre surgery plasma samples from 10 males and 4 females undergoing CEA for symptomatic or asymptomatic stenosis $\geq 70 \%$ were obtained from the Vascular Surgery Unit of Pisa University Hospital and immediately processed at the Institute of Clinical Physiology. Additional 20 plasma samples of CEA candidates and 10 plasma samples of healthy volunteers were collected at the Vascular Surgery Unit of Pisa University Hospital and at the Institute of Clinical Physiology respectively.

Patient characteristics and database information on smoking habit, hypercholesterolemia and diabetes are summarized in Table 1.
Symptomatic patients were classified as CEA candidates who presented with TIA or stroke within 6 months before surgery.

No differences between symptomatic and asymptomatic patients were found for any of the reported parameters. Smokers were classified as individuals who smoked at least three cigarettes per day at the time of analysis, past smokers had quit smoking for at least 6 months, and no-smokers were individuals who had never smoked. Smoker patients were the combined group of the past- and the current-smokers.

Stenosis on ICA was $\geq 70 \%$ at carotid Echocolor Doppler in all patients, whose CEA specimen secretomes were analysed (mean $80 \pm 9 \%$ ), without significant differences between asymptomatic and symptomatic ( $79 \pm 8$ vs $82 \pm 10 \%)$.

\section{Tissue processing and secretome preparation}

The arterial tissue was cultured according to de la Cuesta et al. [12] with modifications. CEA specimens $(n=14)$ from surgery were transported in PBS on ice to the laboratory. Each specimen was crosscut under macroscopic examination to separate P from DS segment. After repeated washing in PBS to remove blood traces, samples were incubated in 6-well plates in $2 \mathrm{ml}$ of Eagle's Minimal Essential Medium (Sigma-Aldrich) supplemented with penicillin and streptomycin, without FBS and phenol red at $37^{\circ} \mathrm{C}$ in a humidified atmosphere of $5 \% \mathrm{CO}_{2}$. After $24 \mathrm{~h}$ the culture medium was harvested, centrifuged at $300 \times \mathrm{g}$ for $10 \mathrm{~min}$ and stored

Table 1 Clinical characteristics of population

\begin{tabular}{|c|c|c|c|c|}
\hline \multirow[t]{2}{*}{ Feature } & & \multirow{2}{*}{$\begin{array}{c}\text { Value }( \pm S D) \\
\text { CEA patients for } \\
\text { secretome }(N=14)\end{array}$} & \multirow{2}{*}{$\begin{array}{c}\text { Value }( \pm S D) \\
\text { CEA patients for plasma } \\
\text { validation }(\mathrm{N}=34)\end{array}$} & \multirow{2}{*}{$\begin{array}{c}\text { Value }( \pm S D) \\
\text { Healthy volunteers } \\
(\mathrm{N}=10)\end{array}$} \\
\hline & & & & \\
\hline \multirow[t]{2}{*}{ Gender } & Females ( $n$ ) & 4 & 10 & 4 \\
\hline & Males (n) & 10 & 24 & 6 \\
\hline Age (years $\pm S D)$ & & $72 \pm 9$ & $74 \pm 7$ & $70 \pm 5$ \\
\hline Symptomatic (n) & & 6 & 11 & - \\
\hline \multirow[t]{2}{*}{ Type of event } & Stroke $(n)$ & 2 & 3 & - \\
\hline & $\mathrm{TIA}(\mathrm{n})$ & 4 & 8 & - \\
\hline Asymptomatic (n) & & 8 & 23 & - \\
\hline Stenosis of ICA $(\% \pm S D)$ & & $80 \pm 9^{*}$ & $79 \pm 8^{*}$ & - \\
\hline Diabetes (n) & & 6 & 9 & - \\
\hline Hypertension (n) & & 10 & 27 & 1 \\
\hline Smoking (n) & & 4 & 13 & 1 \\
\hline Statin treatment $(n)$ & & 10 & 21 & - \\
\hline AntiaggregantTherapy (n) & & 14 & 32 & - \\
\hline Hypercholesterolemia (n) & & 4 & 18 & 2 \\
\hline
\end{tabular}

Categorical values are given as number of patients (n).

Continuous variables are given as mean \pm SD.

TIA: Transient Ischemic Attack. ICA: Internal Carotid Artery.

*Stenosis was measured by carotid EchoColor Doppler. 
at $-80^{\circ} \mathrm{C}$ until analysis. Samples were concentrated by centrifugal devices Amicon Ultra-3 (Millipore) following the manufacturer's recommendations. Protein concentration was determined by bicinchoninic acid (Pierce).

\section{Histology and immunohistochemical characterization}

After 5 to 7 day fixation in $5 \%$ buffered formalin, $\mathrm{P}$ and DS samples were incubated in decalcifying solution (Biooptica 05-M0300 ), washed and dehydrated in ascending alcohols series and embedded in paraffin: transverse $5 \mu \mathrm{m}$ thick consecutive sections were cut from each paraffin block by a rotary microtome (Microm HM 300, Bio-optica). Haematoxylin and Eosin (H\&E) and Masson's trichrome stains were used for histologic analysis. For immunohistochemistry, sections were placed on positively charged slides, de-paraffinized, rehydrated and washed in distilled water; after incubation in $\mathrm{H}_{2} \mathrm{O}_{2}$ at room temperature, antigen retrieval was accomplished (citrate buffer pH6 in microwave for $10 \mathrm{~min}$ at 500W) and then sections incubated with diluted normal blocking serum. Primary antibodies anti- $\alpha$ SMA (alpha smooth muscle actin, clone $1 \mathrm{~A} 4 \mathrm{ADB}$, Serotec) as a SMC phenotype marker, anti-CD68 (mouse, clone PGM1, Thermo Scientific, diluted 1:150) as a macrophage phenotype marker, anti-vinculin (goat polyclonal antibody diluted 1:100, Santa Cruz Biotechnology, Inc.) and antithrombospondin-1 (mouse polyclonal antibody diluted 1:100, Santa Cruz Biotechnology, Inc.) were applied overnight to the slides in a $4^{\circ} \mathrm{C}$ humid chamber.

Following 30 min biotinylated secondary antibody and 30 min Vectastain Elite $\mathrm{ABC}$ reagent incubation in peroxidase substrate solution (DAB), slides were counterstained with Mayer's haematoxylin for $1 \mathrm{~min}$. and mounted (Neo-Entellan Merk). Antibody binding to cells and/or to extracellular components is visible as brown or dark brown stain (DAB), negative cells are stained blue (haematoxylin counterstain).

The same steps had been previously applied to a pool of CEA specimens (from symptomatic and asymptomatic patients) which were processed en bloc and longitudinally, instead of transversely, sectioned by microtome: microscopic examination of the obtained serial sections helped to guide and standardise the splitting of fresh CEA samples, subsequently collected for secretome, into $P$ and DS segments.

Thrombospondin-1 and vinculin double immunostaining was performed using Vectastain Elite $\mathrm{ABC}$ reagent incubation in phosphatase (AP) substrate solution and Permared-AP stain for thrombospondin-1 and DAKO LSAB system HRP and subsequent peroxidase substrate solution (DAB) incubation for vinculin.

All sections from each carotid segment were examined under a light microscope (Olympus BX43) at $4 \times$ to $40 \times$ original magnification and digitized by a video system
(Olympus D70 camera) interfaced to Olympus Cell Sens Dimension software for image acquisition and morphometric analysis. Quantitative analysis of antibody staining within the lesional area of each sample was carried out on several microscopic fields of consecutive sections, digitized at the same light source settings, by double observer colour thresholding: reproducibility and statistical significance of results (expressed as\% positive, dark brown pixels of the entire plaque area) as well as localization of different antibodies on the same region of adjacent sections was thus accomplished.

Carotid plaques were classified according to Stary's stages for atherosclerosis, American Heart Association Committee on Vascular Lesions [19,20].

\section{Reduction, alkylation and digestion}

$100 \mu \mathrm{L}$ of $40 \mathrm{mM}$ ammonium hydrogen carbonate $(\mathrm{pH}=8)$ were added to $100 \mu \mathrm{L}$ of secretome $(1 \mu \mathrm{g} / \mu \mathrm{L}$ concentration). Reduction was obtained by adding $1 \mu \mathrm{L}$ of $1 \mathrm{M}$ dithiothreitol to each sample, with an incubation of $20 \mathrm{~min}$ at $80^{\circ} \mathrm{C}$. For alkylation, $20 \mu \mathrm{L}$ of $100 \mathrm{mM}$ iodoacetamide were added to the samples and incubated for $30 \mathrm{~min}$ at $37^{\circ} \mathrm{C}$. Digestion was performed incubating overnight with $8 \mu \mathrm{L}$ of trypsin solution $(0.25 \mathrm{mg} / \mathrm{mL})$ at $37^{\circ} \mathrm{C}$.

\section{LC-MS/MS analysis}

Chromatographic separation of peptides was performed using an Ultimate 3000 nano-HPLC system (LC Packings, DIONEX, USA). $100 \mu \mathrm{L}$ of filtrate were added to a solution composed by $2 \% \mathrm{ACN}$ and $0.1 \%$ formic acid up to $200 \mu \mathrm{L}$ of final volume. The loading pump preconcentrated the sample in a pre-column cartridge (PepMap-100 C18 5 mm 100 A, $30 \mathrm{~mm}$ id $\times 5 \mathrm{~mm}$ ). Chromatographic separation of peptides was performed using a C18 PepMap-100 column $(15 \mathrm{~cm} \times 75 \mathrm{~mm}$ id, LC Packings DIONEX) equilibrated at $45^{\circ} \mathrm{C}$ with a solvent A (water/acetonitrile 98/2 vol/vol, 0.1\% formic acid)

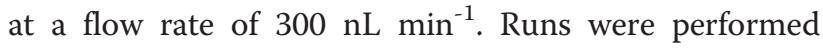
under 60 min linear gradient from 10 to $45 \%$ of solvent B (water/acetonitrile 2/98 vol/vol, $0.1 \%$ formic acid) followed by $10 \mathrm{~min}$ of a purge step at $95 \%$ of B before a 20 min re-equilibration step to the starting conditions. The column was directly coupled to TripleTOF ${ }^{\text {тм }} 5600$ System (AB SCIEX, Toronto, Canada), equipped with a DuoSpray $^{\mathrm{Tm}}$ ion source (AB SCIEX, Toronto, Canada).

Peptides eluted from chromatography were directly processed using TripleTOF ${ }^{\text {тм }} 5600$ mass spectrometer (AB SCIEX, Toronto, Canada). The mass spectrometer was controlled by Analyst ${ }^{\oplus}$ 1.6.1 software (AB SCIEX, Toronto, Canada). For positive ionization, ion source parameters were the following: the spray voltage was $3 \mathrm{kV}$, source temperature $150^{\circ} \mathrm{C}$ with curtain gas set at 25, GS1 10 and GS2 0 psi nitrogen flow. For information 
dependent acquisition (IDA) analysis, survey scans were acquired in $250 \mathrm{~ms}$ and 25 product ion scans were collected if exceeding a threshold of 125 counts per second (counts/s). Total cycle time was fixed to either $1.25 \mathrm{~s}$. Four time bins were summed for each scan at a pulser frequency value of $11 \mathrm{kHz}$ through monitoring of the 40 $\mathrm{GHz}$ multichannel TDC detector with four-anode/channel detection. Dynamic exclusion was set for $1 / 2$ of peak width $(\sim 8 \mathrm{~s})$, and then the precursor was refreshed off the exclusion list.

\section{Protein identification and label-free comparative analysis} MS/MS data were processed with ProteinPilot ${ }^{\text {tw }}$ Software (AB SCIEX, Toronto, Canada), using the Paragon ${ }^{\mathrm{Tw}}$ and Pro Group ${ }^{\text {mi }}$ Algorithms and SwissProt 2011 as protein database for Homo Sapiens. The false discovery rate (FDR) analysis was done using the integrated tools in ProteinPilot software and a confidence level of $95 \%$ was set.

The statistical comparative analysis was performed using MarkerView ${ }^{\mathrm{Tm}}$ Software 1.2.1 (AB SCIEX). The ion chromatograms of high confidence peptides identified by ProteinPilot were extracted using PeakView ${ }^{\text {Tm }}$ Software and then MS peak areas and identifications were imported into MarkerView ${ }^{\text {ma }}$ Software. Normalization of the total plaque size was obtained using a global normalization of profiles (total protein content) using Marker View 1.2 software.

Principal Component Analysis (PCA) was performed in order to evidence groupings among the data set. All profile areas were normalized. The two groups (P and DS) were compared with $t$-test using a threshold of $95 \%$ ( $\mathrm{P}$ value $=0.05)$ and fold change $>2$.

\section{Western blot analysis}

Secretomes were run on a $10 \%$ SDS-PAGE, separated proteins transferred onto a nitrocellulose membrane (Amersham) using a wet transfer system (Biorad). Membranes were blocked with 3\% BSA in TBST for $1 \mathrm{~h}$ at room temperature. Primary and secondary antibodies were diluted in 3\% BSA in TBST. All primary antibodies were incubated overnight at $4^{\circ} \mathrm{C}$. HRP-conjugated secondary antibodies were incubated for $1 \mathrm{~h}$ at room temperature. The following antibodies were used: anti-vinculin goat polyclonal antibody (1:500) (catalog number sc-7648, Santa Cruz Biotechnology, Inc), antithrombospondin-1 mouse monoclonal antibody (1:200) (catalog number sc-73158, Santa Cruz Biotechnology, Inc), and anti- $\alpha$ tubulin mouse polyclonal antibody (1:5000) (catalog number $\mathrm{T}$ 6074, Sigma). Chemiluminescence was detected with $\mathrm{ECL}^{\mathrm{mm}}$ detection kit (Amersham Biosciences, Uppsala, Sweden).

Densitometric quantification of photographic films was performed using Quantity One 1-D Analysis Software
(Bio-Rad). Photographic films were scanned and the pixel intensities of bands was measured subtracting the pixel intensity of the background and all the signals were recorded as Optical Density (O.D.). All the O.D. were reported in graphs and the comparative analyses of the different levels of expression of vinculin and thrombospondin-1 between P and DS samples was done integrating the resulting area under curve by using Origin 7.0 (Originlab).

\section{ELISA assays}

Dosage by double-antibody sandwich enzyme-linked immunosorbent assay (ELISA) was performed on vitamin $\mathrm{D}$ binding protein and thrombospondin-1.

ELISA kits were used and reagents were prepared following the manufacturer's manual. Briefly, for vitamin D binding protein (Uscn Life Science Inc, Wuhan, China) the calibration curve ranged between 10 and $0.156 \mathrm{ng} /$ $\mathrm{mL}$ (considering a dilution for plasma samples of 200000 -fold) and the calibrator diluent was used as the zero standard. All standards and samples were assayed in duplicates.

For thrombospondin-1 assay (Bio Medical Assay, Beijing, China) the calibration curve ranged between 20 and $0.312 \mathrm{ng} / \mu \mathrm{L}$. Plasma samples were diluted 100 fold.

The ELISA assay for Vitamin D binding protein (Quantikine ${ }^{\circ}$ ELISA Human Immunoassay- USA \& Canada R\&D Systems, Inc.) was performed also on secretome samples without dilution. The calibration curve ranged between $1000 \mathrm{ng} / \mathrm{ml}$ and $15.5 \mathrm{ng} / \mathrm{ml}$. The absorbance was read at $450 \mathrm{~nm}$ with a Fluorstar (Omega) microplate reader (Molecular Devices, Sunnyvale, CA).

\section{Statistical analysis}

Principal component analysis (PCA) was conducted on mass spectrometric data of samples using Marker View 1.2 software.

Student's $t$ Test was used as statistical parameter between the means of continuous variables to determine significant differences between categories of mass spectrometric data. $P$ value $<0.05$ were considered significant to validate differences between categories and fold change $>2$.

Statistical analyses of other data were conducted using Origin 7.0 software. Data are expressed as the mean \pm SD. Differences between the means of the 2 continuous variables were evaluated by the Student's $t$ Test and results accepted when $t$ Test $>95 \%$ and $\mathrm{P}$ value $<0.05$. Paired $t$ test was used for quantitative immunohistochemistry and ELISA assay.

\section{Ingenuity pathway analysis (IPA)}

IPA (http://www.ingenuity.com/products/pathways_analysis. html) was performed on a restricted and selected number of identified proteins $(n=56)$ from the secretomes of CEA 
specimens. The subset of chosen proteins was constituted of 34 extracellular matrix proteins, 9 plasma membrane proteins and 13 intracellular proteins. This subset of proteins was related to five function/disease pathways: migration of cells $(n=39)$, proliferation of smooth muscle cells $(n=9)$, vascular disease $(n=11)$, atherosclerotic lesion $(n=8)$ and angiogenesis $(n=22)$. Colored points were used to evidence differentially released proteins between P and DS.

\section{Results}

\section{Morphological characterization}

Microscopic examination of longitudinal sections of undivided CEA specimens evidences a plaque core containing area $(\mathrm{P})$ comprised of typical components (lipid-rich necrotic core, fibrous cap, cholesterol clefts, large calcium deposits, intraplaque haemorrage/ fresh thrombi) and the distal side segment (DS) with fibromuscular tissue, small extracellular lipid and calcium deposits. Fresh CEA specimens for secretome were subsequently divided to separate central plaque $\mathrm{P}$ from its distal side DS, as depicted in Figure 1.

Sections from all CEA specimens, each cut in two (P and DS) were examined and classified for the presence of histologic hallmarks of atherosclerosis, including lipid-rich necrotic core, cholesterol clefts, fibrosis, calcium, thin fibrous caps, macrophage infiltrate, neovessels, intraplaque haemorrhage/thrombi. The DS segments, although free of grossly evident changes, showed small lesions at histologic examination, with atherosclerotic features similar to those classified as Stary's types III and IV. Proximal P segments, on the other hand, showed grossly evident fibrolipidic and/ or fibrocalcific, mostly complicated plaques classified as types V and VI (Table 2) [19,20].

Masson's trichrome stain, $\alpha \mathrm{SMA}$ and CD68 immunostaining representative of $\mathrm{P}$ and DS segments are shown in Figure 2; the quantitative analyses for $\alpha \mathrm{SMA}$ and CD68 are also reported, demonstrating a significantly higher content of VSMCs and CD68 positive macrophages in the distal side as compared to central plaque region (Figure 2).

\section{Secretome analysis of endarterectomy specimens}

$\mathrm{P}$ and DS segments from the 14 enrolled patients were incubated for $24 \mathrm{~h}$ in serum free medium, secretomes were collected, protein digested and peptides fractionated by reverse phase chromatography and analyzed by 5600 TripleTOF mass spectrometer.

Using this LC-MS/MS approach, 463 proteins were identified with a Protein Score (Confidence) > 95\% and using local false discovery rate analysis $>1 \%$ as stringent criterion to avoid false positives (Additional file 1: Table S4 and Additional file 2: Table S5). The entire list of

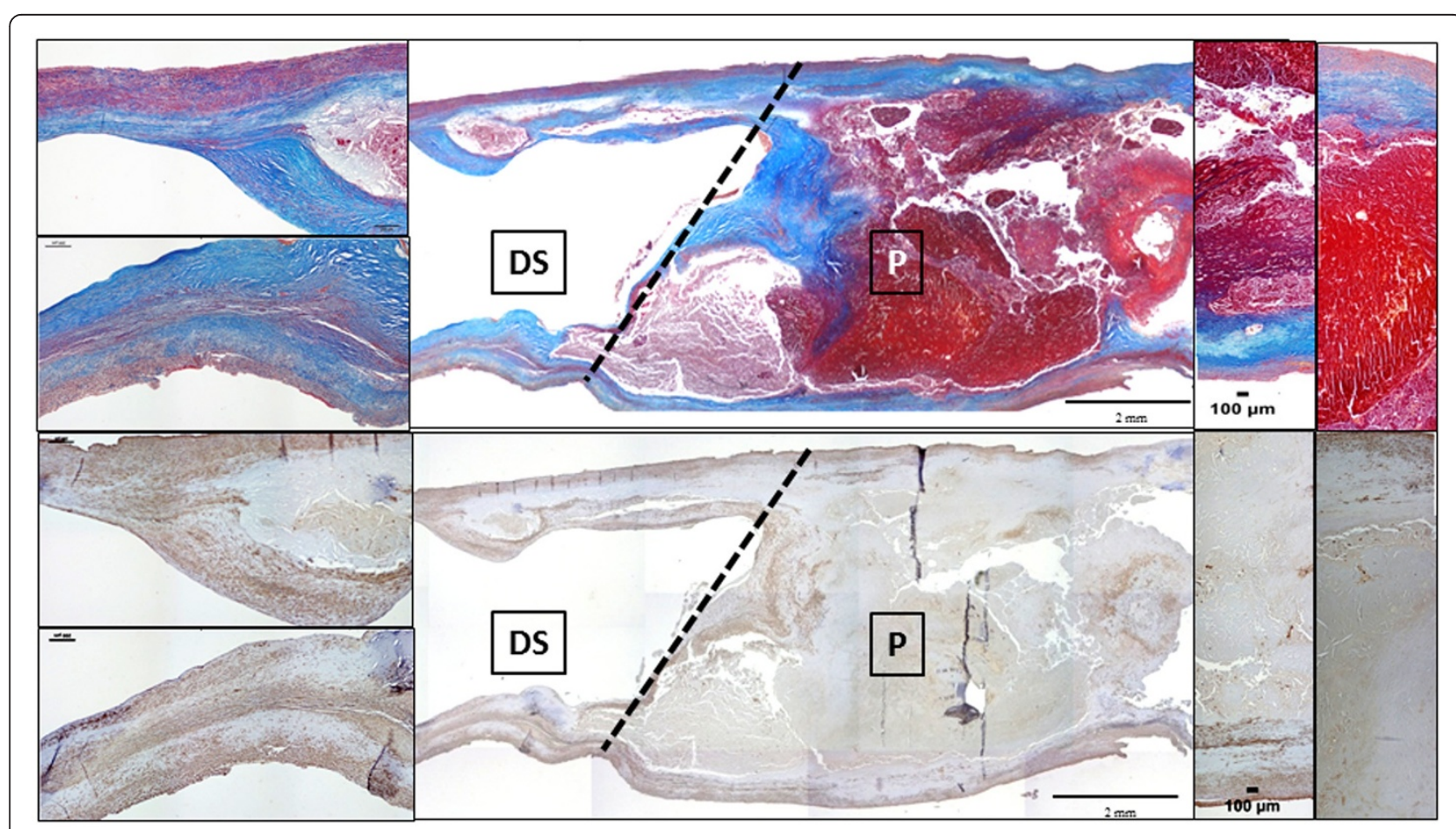

Figure 1 Longitudinal section of an undivided CEA specimen at artery center line level showing the cutting line for P and DS segments separation. Prevalent complicated plaque features of $\mathrm{P}$ (lipid-necrotic core, calcium deposits, fibrosis and haemorrage) and milder changes of its downstream side DS (prevalent VSMCs and collagen component, small lipid and calcium deposits) are evidenced by Masson's trichrome and a-SMA immunostaining (from top to bottom). Original magnification $2 x$, insets $10 x$ 
Table 2 Histologic characterization of $P$ and DS samples

\begin{tabular}{lcc}
\hline & P (\% specimens) & DS (\% specimens) \\
\hline TFCA(1) & 33 & 0 \\
$\mathrm{Ca}(2)$ & 65 & 10 \\
$\mathrm{NC}-\mathrm{Chol}(3)$ & 75 & 20 \\
$\mathrm{He}(4)$ & 35 & 0 \\
\hline
\end{tabular}

(1) TFCA= thin fibrous cap, (2) $\mathrm{Ca}=$ calcification, (3) NC-Chol=necrotic core cholesterol clefts.

(4) $\mathrm{He}=$ intraplaque hemorrhage/thrombus.

proteins reported in supplementary tables was analyzed in the context of the published literature and firstly grouped as extracellular and intracellular proteins. Using Uniprot database (www.uniprot.com), extracellular proteins were further subdivided in ECM proteins and ECMassociated proteins. The intracellular ones were grouped considering their localization in cytosol, membrane, organelle, cytoskeleton and others (Figure 3A).

The secretion potential of these identified proteins was computed by submitting them to SecretomeP server that predicts protein secretion route on the basis of the presence of the signal peptide, responsible for endoplasmic reticulum addressing. The non-classical secretion through multi vesicular bodies was also determined by SecretomeP using specific databanks [21] (Figure 3B).

\section{Comparative analysis between plaque and its distal counterpart secretomes}

In order to evaluate differentially released proteins between P and DS specimens, MarkerView 1.2 software was used and 31 proteins were found differentially

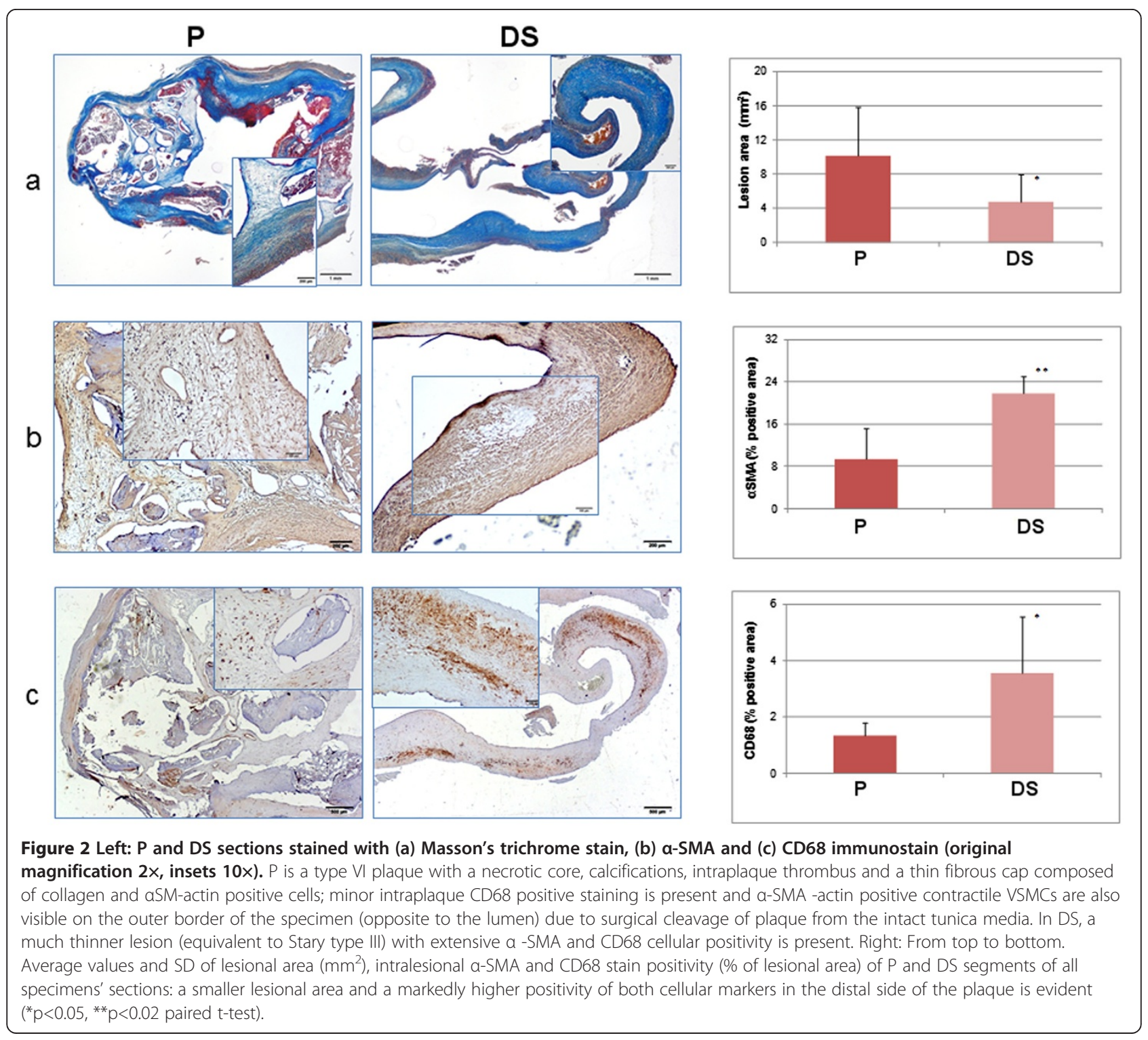




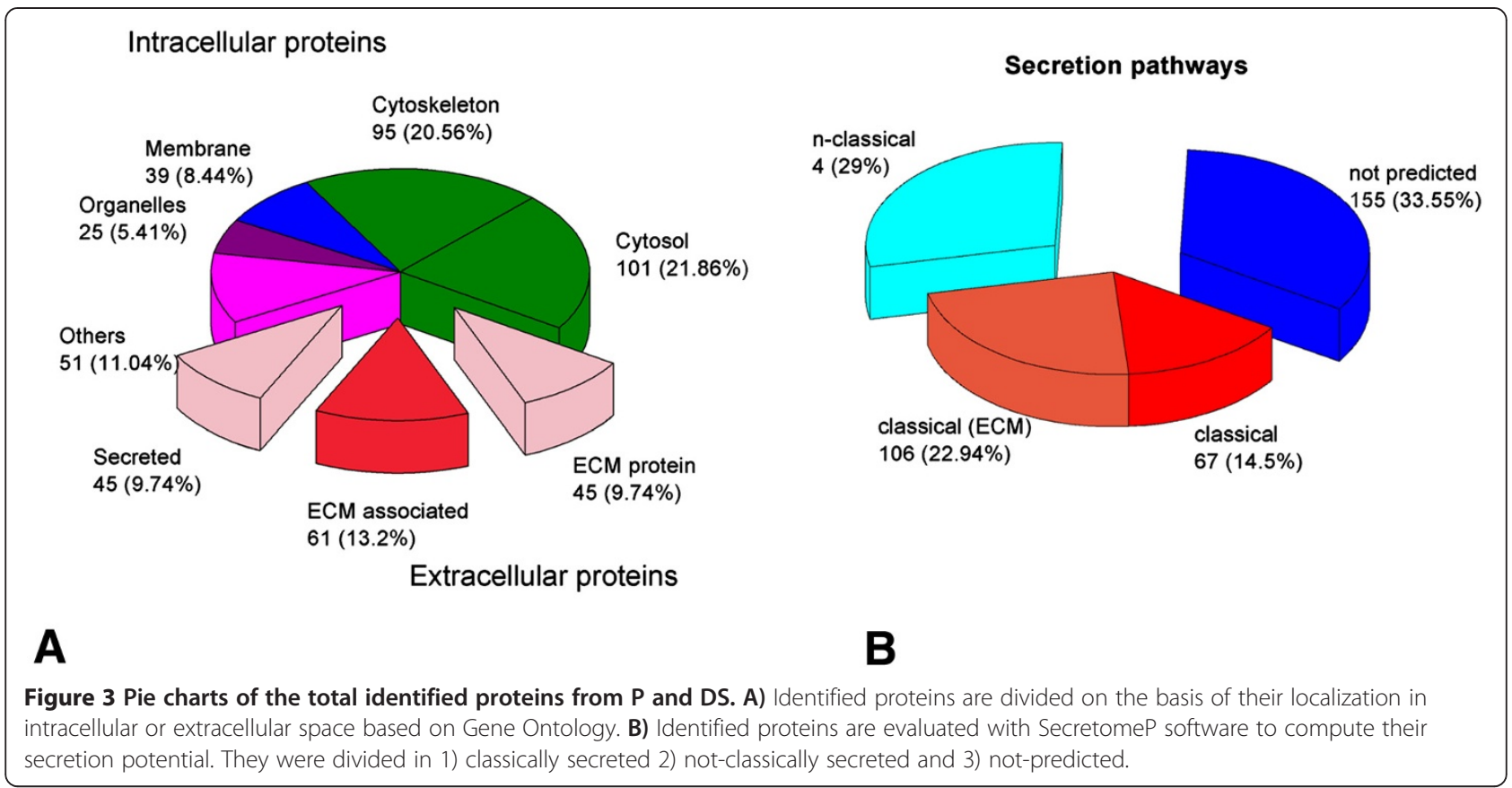

secreted. These proteins were classified into two categories: cellular $(n=17)$ and extracellular proteins $(n=14)$ (Table 3). The putative role of each factor in atherosclerosis and cardiovascular disease was reported in the table as suggested by the literature, in order to underline a possible correlation of their dis-regulation to the pathology.

Nine out of the 14 extracellular proteins were found over-expressed in $\mathrm{P}$ secretome, whilst cellular proteins were found over-expressed in DS secretome, with the exception of smoothelin, which is a recognized marker of VSMC contractile phenotype [23]. Of these proteins eighteen have been already reported in serum/plasma and listed in Human Protein Reference database (www. hprd.org). Origin 7.0 was used to represent the modulation of the differentially released proteins and the most interesting are reported as representatives of the results (Figure 4).

\section{Validation by Western Blot and ELISA assay}

Western Blot analysis and also ELISA assay were applied to secretomes in order to validate the differential release observed by mass spectrometric analysis. Vinculin and thrombospondin-1 were selected for Western blot validation (Figure $5 \mathrm{~A}$ ), while vitamin $\mathrm{D}$ binding protein was selected for ELISA assay (Figure 5B).

\section{Immunohistochemistry quantification}

Double immunostaining of anti-vinculin and antithrombospondin-1 antibodies on P and DS sections of a CEA specimen is shown in Figure 6. Anti-vinculin antibody selectively stains lesional cells whereas thrombospondin-1 stain is confined to the plaque lipid-necrotic core and surrounding fibrous cap.

Quantitative results derived from single immunostaining of both markers on sections of all CEA specimens confirm the significantly higher $(6.4 \pm 5.0$ vs $3.4 \pm 3.0$ $\mathrm{P}<0.02)$ vinculin positivity and the much lower $(0.8 \pm 0.8$ vs $7.3 \pm 6.0 \quad \mathrm{P}<0.02)$ thrombospondin-1 positivity in the lesion area of DS as compared to corresponding $\mathrm{P}$ segments.

\section{ELISA assay of plasma samples}

Dosage by double-antibody sandwich ELISA assays of thrombospondin-1 and vitamin D binding protein were performed in plasma samples of 34 CEA patients and 10 age-matched healthy controls. As reported in Table 1, 11 patients were symptomatic while 23 were asymptomatic. Plasma levels of thrombospondin-1 and vitamin D binding protein were significantly higher in atherosclerotic patients than in healthy subjects (thrombospondin-1: $71 \pm 20$ vs $48 \pm 9 \mathrm{ng} / \mathrm{mL}$ P value $=0.02$; Vitamin D binding protein: $205 \pm 133$ vs $76 \pm 8 \mathrm{ng} / \mathrm{mL} \mathrm{P}$ value $=0.05)$, while no significant differences were observed between symptomatic and asymptomatic patients (thrombospondin-1: $67 \pm 14$ vs $72 \pm 20 \mathrm{ng} / \mathrm{mL}$ P value $=0.72$; vitamin $\mathrm{D}$ binding protein: $234 \pm 137$ vs $192 \pm 122 \mathrm{ng} / \mathrm{mL} \quad \mathrm{P}$ value $=0.69$ ) (Figure 7).

\section{Discussion}

Several proteomics approaches have been carried out on in order to clarify the mechanisms of atherogenesis as well as to search for plaque presence and severity. The majority of these studies concern carotid atherosclerosis. 
Table 3 Differentially released proteins by CEA specimens

\begin{tabular}{|c|c|c|c|c|c|c|}
\hline Localization & Protein name (1) & $\begin{array}{l}\text { Gene } \\
\text { name }\end{array}$ & Role in atherosclerosis (2) & $\begin{array}{c}\text { P/DS } \\
(3)\end{array}$ & $\begin{array}{l}P \text { value } \\
(4)\end{array}$ & $\begin{array}{l}\text { Plasma } \\
(5)\end{array}$ \\
\hline \multirow[t]{17}{*}{ Cellular } & Alpha-actinin 1 & ACTN1 & Focal adhesion & $\boldsymbol{\nabla}$ & $6.70 \mathrm{E}-04$ & $\nabla$ \\
\hline & Integrin-linked protein kinase & ILK & Focal adhesion & $\boldsymbol{\nabla}$ & 1.10E-04 & $\nabla$ \\
\hline & Actin-related protein $2 / 3$ & ARPC3 & Focal adhesion & $\boldsymbol{\nabla}$ & $1.20 \mathrm{E}-04$ & $\nabla$ \\
\hline & Filamin A & FLNA & Focal adhesion & $\boldsymbol{\nabla}$ & $1.35 \mathrm{E}-05$ & $\nabla$ \\
\hline & PDZ and LIM domain protein 1 & PDLI1 & Focal adhesion & $\boldsymbol{\nabla}$ & $1.34 \mathrm{E}-03$ & $\nabla$ \\
\hline & PDZ and LIM domain protein 7 & PDLI7 & Focal adhesion & $\boldsymbol{\nabla}$ & 5.70E-04 & $\nabla$ \\
\hline & Vimentin & VIM & Focal adhesion & $\boldsymbol{\nabla}$ & 2.02E-03 & $\nabla$ \\
\hline & Vinculin & VCL & Focal adhesion [12] & $\boldsymbol{\nabla}$ & $2.80 \mathrm{E}-04$ & $\nabla$ \\
\hline & Cysteine-rich protein 2 & CRIP2 & SMC differentiation [22] & $\boldsymbol{\nabla}$ & 1.10E-04 & \\
\hline & Calponin 1 & CNN1 & SMC differentiation & $\boldsymbol{\nabla}$ & $1.90 \mathrm{E}-04$ & \\
\hline & Calponin 2 & CNN2 & SMC differentiation & $\boldsymbol{\nabla}$ & 2.57E-03 & $\nabla$ \\
\hline & Calponin 3 & CNN3 & SMC differentiation & $\boldsymbol{\nabla}$ & 1.10E-04 & \\
\hline & Transgelin & TAGL & SMC differentiation & $\boldsymbol{\nabla}$ & 3.00E-03 & \\
\hline & Tropomyosin-1 alpha & TPM1 & SMC differentiation & $\boldsymbol{\nabla}$ & $2.63 \mathrm{E}-03$ & $\nabla$ \\
\hline & Tropomyosin beta & TPM2 & SMC differentiation & $\boldsymbol{\nabla}$ & 1.14E-03 & $\square$ \\
\hline & Smoothelin & SMOO & $\begin{array}{l}\text { SMC differentiation and plaque } \\
\text { stability [23] }\end{array}$ & $\Delta$ & $3.40 \mathrm{E}-04$ & $\square$ \\
\hline & $\begin{array}{l}\text { Vascular cell adhesion protein } 1 \\
\text { (VCAM-1) }\end{array}$ & VCAM1 & Monocyte recruitment & $\boldsymbol{\nabla}$ & 1.39E-02 & $\square$ \\
\hline \multirow{14}{*}{$\begin{array}{l}\text { Extracellular matrix } \\
\text { (ECM) }\end{array}$} & Collagen alpha 1 (III) & COL3A1 & Plaque stability & $\Delta$ & $1.70 \mathrm{E}-04$ & \\
\hline & Collagen alpha $1(\mathrm{VI})$ & COL6A1 & Plaque stability & $\Delta$ & 2.40E-04 & \\
\hline & Collagen alpha 1 (XIV) & COL14A1 & Atherogenesis & $\Delta$ & $1.05 \mathrm{E}-03$ & \\
\hline & Collagen alpha 1 (XVI) & COL16A1 & Atherogenesis & $\Delta$ & 2.07E-03 & \\
\hline & Versican & VCAN & Atherogenesis [24] & $\Delta$ & $1.45 \mathrm{E}-05$ & \\
\hline & Lumican & LUM & Plaque rupture [24] & $\Delta$ & 4.07E-02 & $\square$ \\
\hline & Fibulin 2 & FBLN2 & Cell migration [25] & $\Delta$ & 9.00E-03 & \\
\hline & Emilin 1 & EMILIN1 & Elastic lamellae integrity [26] & $\boldsymbol{\Delta}$ & $1.82 \mathrm{E}-03$ & $\nabla$ \\
\hline & Periostin & POSTN & Angiogenesis & $\Delta$ & 2.07E-03 & \\
\hline & Thrombospondin-1 & THBS1 & Angiogenesis [27] & $\Delta$ & $1.71 \mathrm{E}-02$ & $\square$ \\
\hline & Vitamin D binding protein & GC & Acute events $[28,29]$ & $\Delta$ & 1.93E-02 & $\nabla$ \\
\hline & Apolipoprotein A-II & APOA2 & Lipid transport & $\Delta$ & $1.28 \mathrm{E}-03$ & $\nabla$ \\
\hline & Apolipoprotein D & APOD & Lipid transport & $\Delta$ & $3.11 \mathrm{E}-05$ & $\nabla$ \\
\hline & Aggrecan & ACAN & Lipoprotein retention & $\Delta$ & 1.51E-05 & \\
\hline
\end{tabular}

(1) Protein name is reported according with SwissProt 2011 database. (2) Role in atherosclerosis is referred to data reported on the recent literature (3) $\mathbf{V}:$ down released in P compared with DS; $\mathbf{\Lambda}$ : up released in P vs DS. (4) P values were generated using Marker View software. (5) Their presence in plasma was showed according to Human Protein Reference database (www.hprd.org).

All these studies, due to technical limits as well as to low sensitive and low-throughput methods, identified only a small number of proteins, restricting considerably the detection of novel low abundant biomarkers.

Lepedda et al. [6] identified 9 differentially expressed proteins in unstable compared to stable plaques while, only one year later, Olson et al. [7] suggested 19 proteins with a differential distribution in stable compared to more complicated carotid segments of the same patients. To increase sensitivity in the search of new biomarkers, high-throughput western blot analyses and microarray technology were performed allowing the finding of 7 differentially expressed proteins [8] and 11 proteins distributed between stable and unstable plaques [30]. A tissue proteomics study has recently identified and demonstrated that osteopontin tissue expression in carotid plaques and its plasma levels are predictive of adverse cardiovascular events in all atherosclerotic vascular districts [9].

One of the first pioneering secretome studies, using twodimensional gel electrophoresis, allowed the identification 


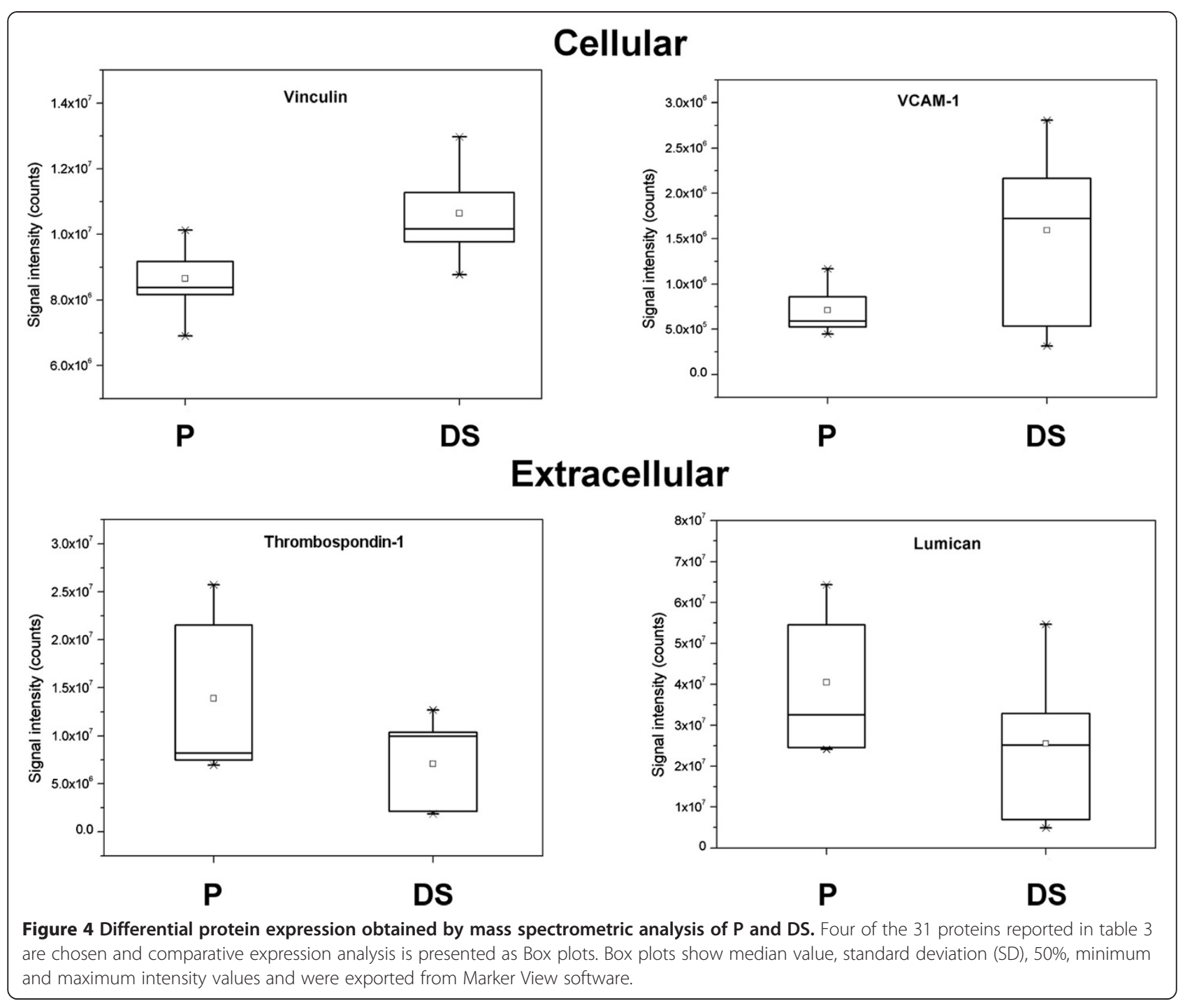

of 14 proteins secreted by autoptic human coronary artery segments [12], but only recently, in order to avoid high abundant plasma protein contamination, CooksleyDecasper and colleagues [13] studied the secretomes from carotid plaques combining antibody phage display with mass spectrometry. This last approach couples sensitivity and accuracy providing a direct detection of secreted proteins in blood. The method is quite complex respect to the full-screen untargeted approach chosen in our study and the number of identified proteins is rather limited, thus restricting the "discovery potential" of that approach.

In our study the secretome of human carotid plaques was tackled with a high performance, very sensitive, geland label-free LC-MS/MS workflow. The unbiased approach, able to give a high sensitive full screen overview of secreted proteins from human carotid artery, is presented here for the first time. This method allowed the identification of 463 proteins thus producing a wide shot on proteins released by atherosclerotic arteries. The majority of the identified proteins (70\%) are predicted as secretory proteins by SecretomeP software. $40 \%$ of these, due to the presence of the characteristic signal peptide, are likely to follow the classical exocytosis pathway across the Golgi apparatus. The other proteins are nonclassically secreted through microvesicles and multi vesicular bodies-derived exosomes, as evidenced by the inclusion in ExoCarta databank (http://www.exocarta.org).

In our procedure, CEA specimens were cut in $\mathrm{P}$ and downstream DS segments in order to compare the secretomes of the upstream area of maximum stenosis to that of partially preserved downstream area, subjected to distinct flow shear stress and wall strain regimen. P segments were classified as Stary's types V and VI $[19,20]$, while DS segments displayed less severe wall changes. We considered this approach useful to differentiate specific molecular factors of the central plaque area, where complication features are present, from those of its distal side. 

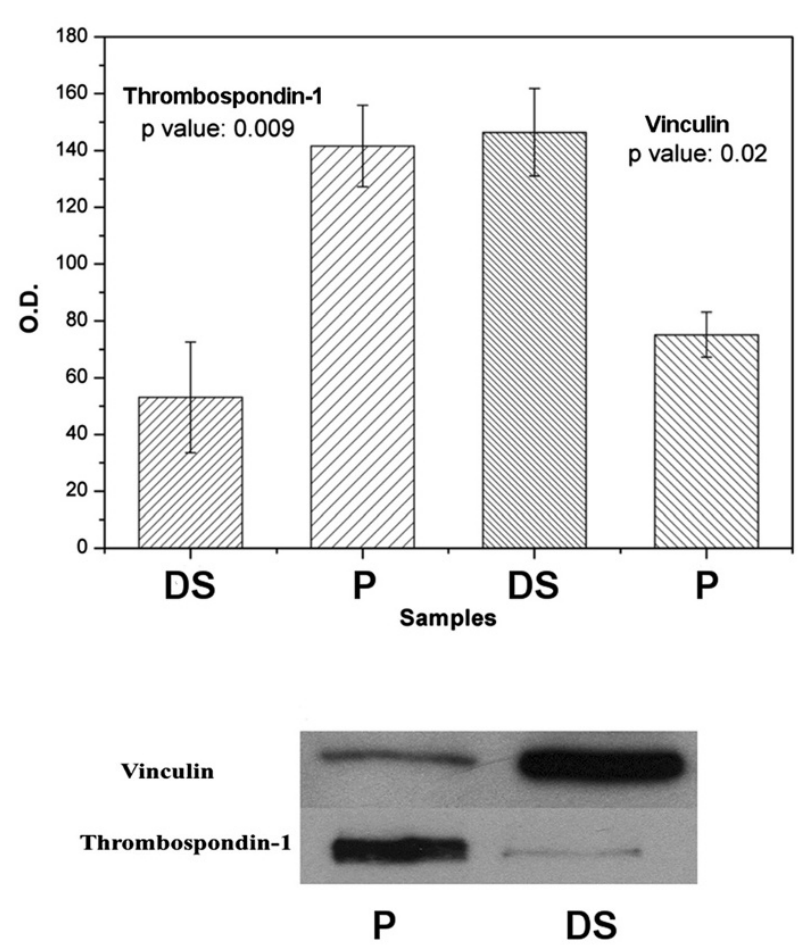

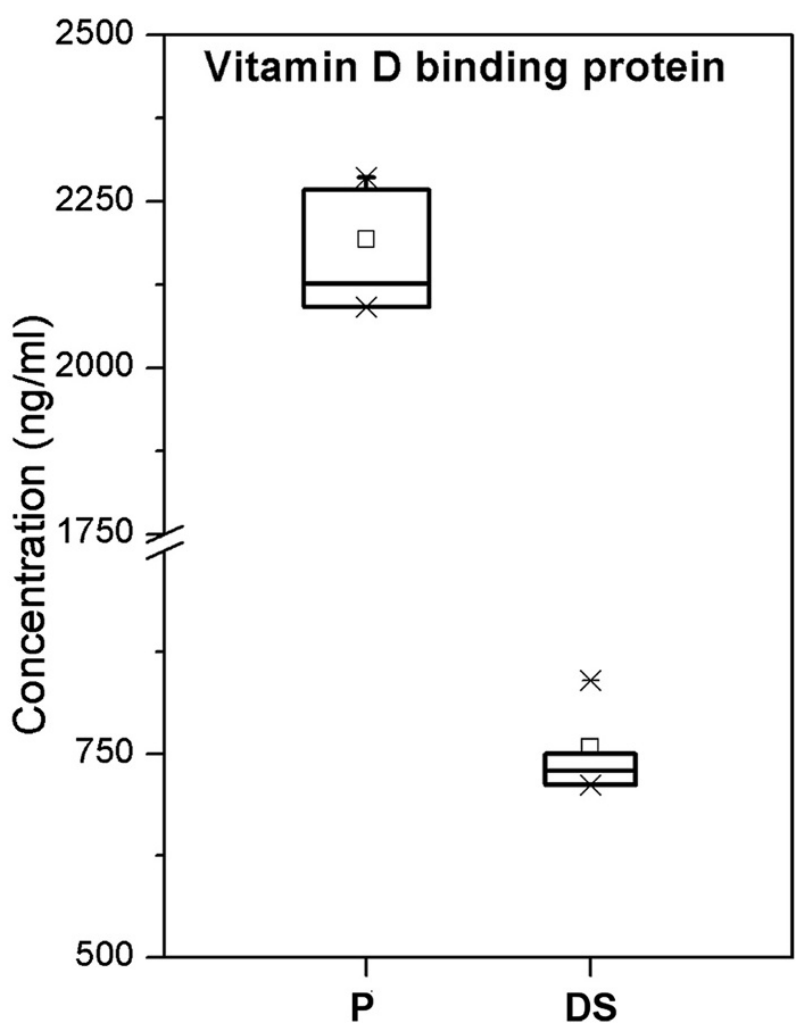

Figure 5 Left: Western blot analysis of P and DS secretomes. Densitometric quantification of vinculin and thrombospondin-1 using Quantity One 1D analysis software. Representative images: $10 \mu \mathrm{g}$ of proteins were separated on SDS-PAGE and blotted on nitrocellulose membrane. Immunoblots were probed with antibodies against vinculin and thrombospondin-1. Right: ELISA assay for vitamin D binding protein expression in secretome samples (P and DS).

Indeed, while the majority of the hitherto performed studies have been focused on plaque classification and are based on cross-sectional observations, without taking into account the longitudinal heterogeneity and asymmetry within the atherosclerotic CEA specimens, it has been recently recognized that the upstream side is associated with an increased incidence of severe lesions with cap rupture, while the downstream side is associated with higher VSMC content and it could thus be more representative of cellular growth $[14,17,18]$.

According to this line of reasoning, we found that proteins involved in ECM organization are more represented in P secretome while proteins concerning VSMC phenotype switch, cell contraction and migration, as well as focal adhesion pathways are more abundantly released by DS segments. These observations confirm and strengthen the role of VSMC activation in the early stages of plaque development [31,32] and, conversely, the role of ECM substrates and matrix remodeling in mature plaques $[24,26]$.

Pathway analysis was chosen to relate identified proteins to their cell function and/or pathological role in vascular diseases. As evidenced by IPA clusters (Figure 8) almost all proteins reported as involved in atherosclerotic lesion and vascular disease are also related to migration and proliferation of cells, reinforcing the primary role of VSMCs in plaque progression.

Secretome expression of vinculin and thrombospondin-1 have been validated by western blot analyses: the first one being an intracellular protein, involved in cell migration, the latter one as representative of ECM-related proteins and reported to control atherosclerotic plaque maturation $[12,27]$. Single and double immunostaining confirmed western blot results of differential protein distribution along CEA specimens, at the same time excluding significant tissue colocalization. A sandwich ELISA assay was also used to confirm the differential secretion of vitamin D binding protein, an extracellular protein reported as marker of acute events $[28,29]$. Both western blots and ELISA tests validated the mass data on secretomes.

Amongst the 463 identified proteins, 31 resulted differentially secreted by $\mathrm{P}$ and DS samples. Half of them were extracellular factors, most of which already reported in plasma, according to Human Protein Reference Database, suggesting that, once released from tissue, they could be found in peripheral blood. For this reason, vitamin $\mathrm{D}$ binding protein and thrombospondin-1 were measured in plasma samples of CEA candidates and 

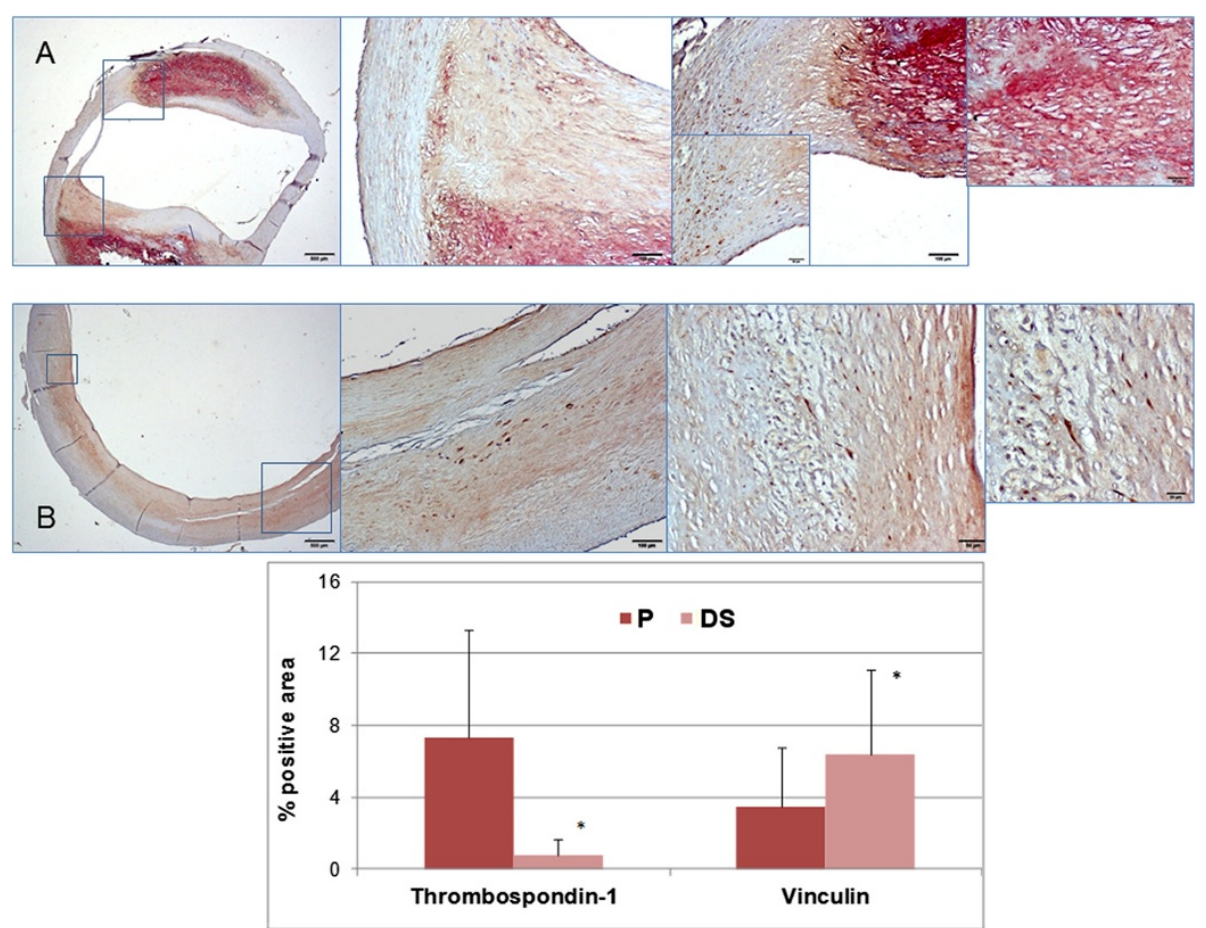

Figure 6 Top: Double immunostaining of thrombospondin-1 (red) and vinculin (brown) in P (A) and DS (B) sections of a fibrocalcific type $\mathrm{Vb}$ plaque. Low magnification ( $2 x$, left) and high magnification (10x to $40 x$ ) microscopic fields (insets) are shown. Neither cellular nor extracellular co-distribution of the two antibodies is present. A selective cellular binding of vinculin both on P an DS sections is evident, while thrombospondin-1 is almost exclusively located in the fibrocalcific core of P. Bottom: Average values and SD of thrombospondin-1 and vinculin positivity (single immunostaining) in lesional area of all CEA specimens showing a markedly greater stain in P as compared toDS for thrombospondin-1 and an opposite pattern for vinculin. ${ }^{*} \mathrm{p}<0.02$ paired t-test.

found significantly higher than in non atherosclerotic subjects. No significant association with symptomatology was evidenced. The correlation between secretome modulation and plasma levels of these two proteins confirms that tissue-secreted protein analysis can be helpful to search for novel disease-specific biomarkers in blood and improve non-invasive risk assessment.

The clinical impact of secretome approach to vascular pathology and atherosclerosis arises from the potential use of plaque-secreted molecules as useful predictors of
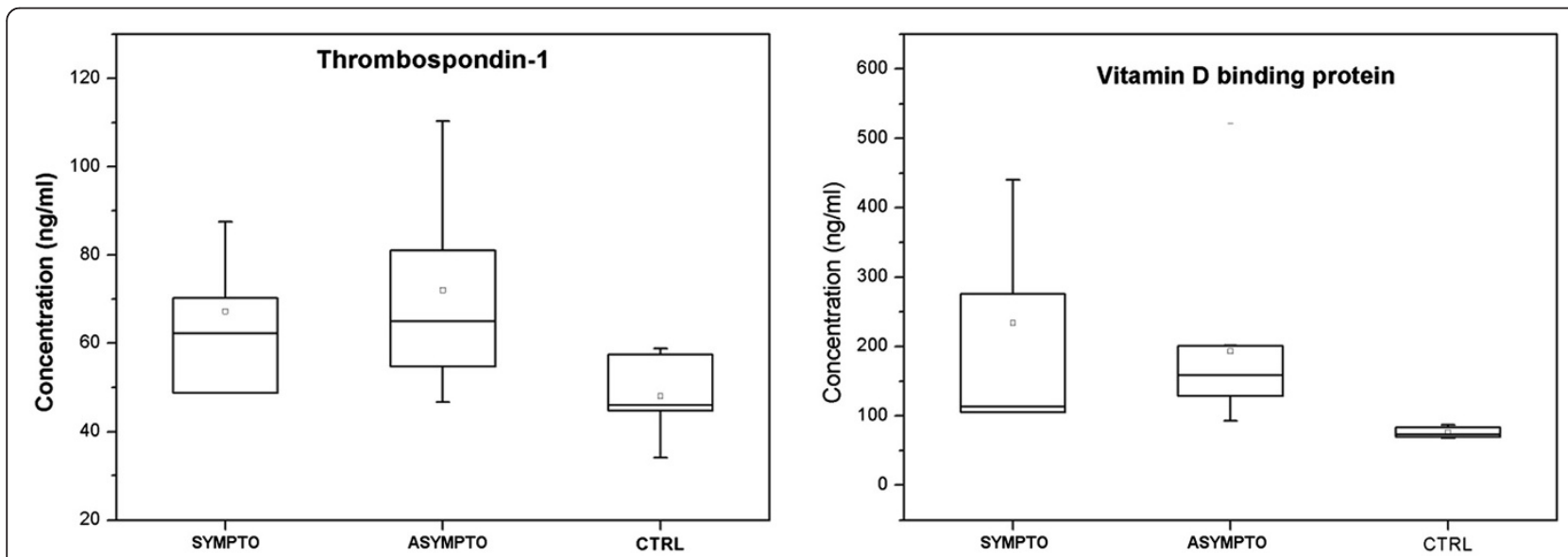

Figure 7 ELISA assay for thrombospondin-1 and vitamin D binding protein expression in plasma samples of 34 CEA patients classified as symptomatic and asymptomatic and 10 healthy controls. 


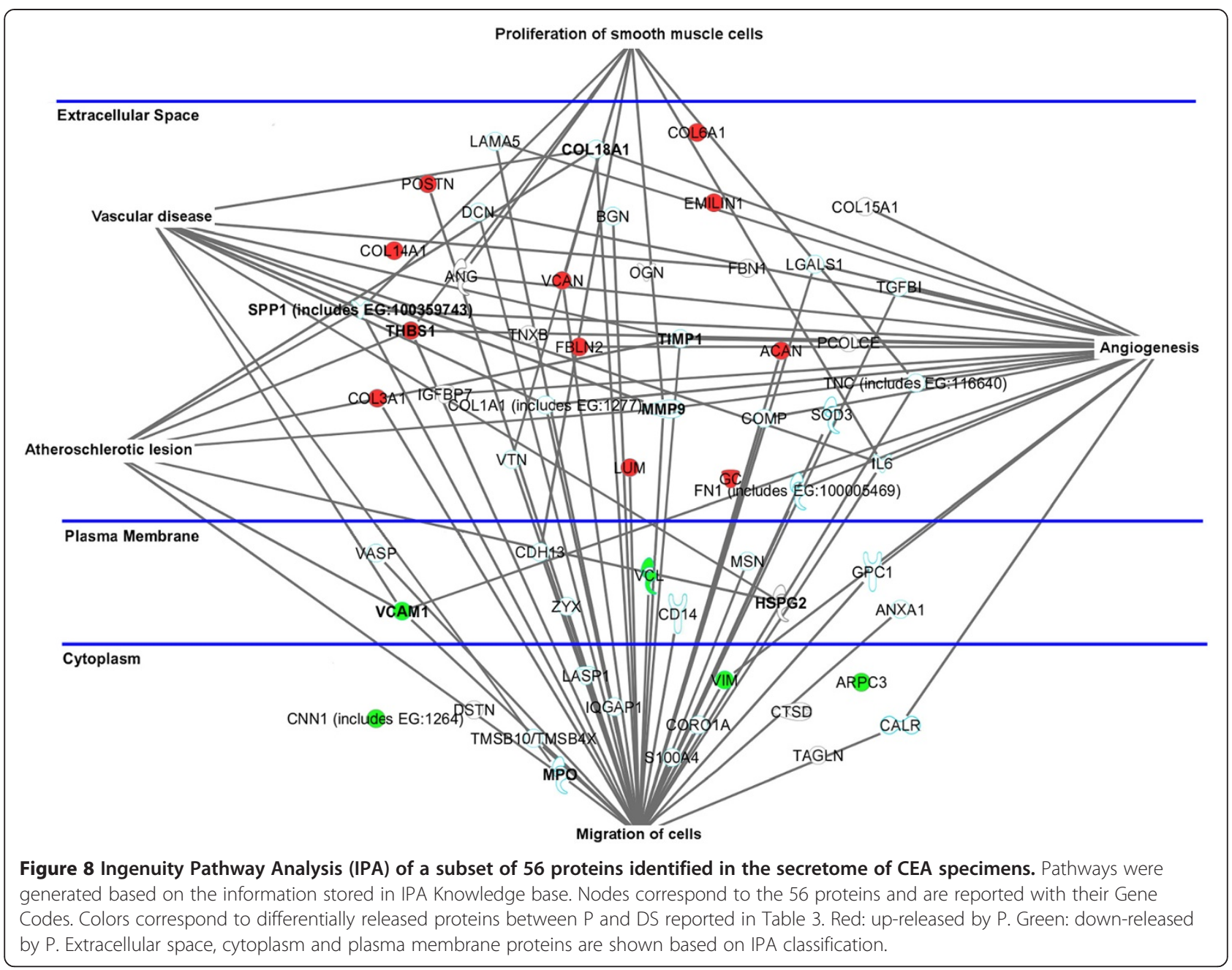

disease outcome and/or of risk assessment. An untargeted secretome strategy can be able to differentiate progressing from stable plaques as well as discriminating rupture-prone from non-vulnerable plaques, leading to a proper selection and optimal management of high risk patients [10].

This potentiality is challenged by clinical and biological limitations: (a) atherothrombosis accounts for no more than $20 \%$ of strokes; (b) complicated ruptured plaques can be asymptomatic, limiting markers specificity; (c) site-specificity of arterial VSMCs and extent of plaque vascularization can influence type and quantity of proteins released in the blood.

Despite these restrictions, secretome analysis seems a most valuable tool to disclose the molecular basis of atherosclerosis as well as of several other diseases [33], due to the unique combination of tissue specificity of biomarkers and clinical feasibility of their detection in blood, aimed to improve patient diagnosis and monitoring.

Results of an untargeted secretome analysis are presented in this study: this unbiased strategy, as compared to targeted analysis, may complicate a prompt clinical output but it is surely the most adequate approach to unravel novel disease markers.

The relatively small number of CEA specimens analyzed represents a limit and the lack of sample stratification is the most relevant consequence of this fact. Despite that, our high sensitive method evidences a very broad spectrum of proteins in carotid plaque secretome and comparative analysis between P and its DS overrides inter-patient variability.

Two ECM proteins released by $\mathrm{P}$ are found significantly higher in plasma from atherosclerotic patients without differences between symptomatic and asymptomatic ones, supporting the mismatch between plaquerelated and event-related factors, in agreement with other findings [9].

A further clinical relevance of the present study relies on the evidence that a large number of CEA secreted proteins are asymmetrically distributed along the atherosclerotic vessel, related to plaque complication features: this implies that a broader cellular and extracellular 
protein profiling, rather than isolated marker assays, may be required to increase specificity and predictive potentiality. Future studies are needed to specify secretome-plasma proteins profiling at different stages of carotid plaque growth and complication and its relation to clinical events.

\section{Conclusions}

Thanks to an optimized workflow, a detailed, broad spectrum profile of the human carotid plaque secreted proteins has been obtained. A large number of CEA-secreted proteins are evidenced which result asymmetrically distributed along the atherosclerotic vessel according to their cellular or extracellular origin, suggesting that markers of stable plaque growth and those of plaque complication could be exploited as biomarkers of distinct and specific stages of disease.

\section{Additional file}

Additional file 1: Table S4. Cellular identified proteins using LC- MS/ MS approach.

Additional file 2: Table S5. Extra cellular identified proteins using LC- MS/MS approach.

\section{Competing interests}

The authors declare that they have no competing interests.

\section{Authors' contributions}

SRoc, AC and MGT conceived and designed the study. MF and MM performed CEA and collected clinical data. AC set up CEA secretomes. SRoc and SRos performed LC-MS/MS workflow. SRoc and GP analyzed data. SRos and AC performed western blots and ELISA assays. FV and GP performed histology and immunohistology. GP and SRoc wrote the manuscript. LC, MGT, GP and SRoc revised the manuscript. All authors read and approved the final manuscript.

\section{Acknowledgements}

This work was partially funded by ARTreat FP7 project (Grant Agreement FP7 224297) and by Fondazione Cassa di Risparmio di Pisa in the framework of the MICROVAST project.

\section{Author details}

${ }^{1}$ National Research Council, Institute of Clinical Physiology, Via Moruzzi, Pisa, Italy. ${ }^{2}$ University of Pisa, Unit of Vascular Surgery, Via Paradisa, Pisa, Italy. ${ }^{3}$ University of Pisa, Department of Clinical and Experimental Medicine, Via Volta, Pisa, Italy.

Received: 10 July 2013 Accepted: 18 September 2013 Published: 16 October 2013

\section{References}

1. Lusis AJ: Atherosclerosis. Nature 2000, 407:233-241.

2. Libby P, Ridker PM, Hansson GK: Progress and challenges in translating the biology of atherosclerosis. Nature 2011, 473:317-325.

3. Touzé E, Mas JL, Röther J, Goto S, Hirsch AT, Ikeda Y, Liau C-S, Ohman EM, Richard AJ, Wilson PWF, Steg PG, Bhatt DL: Impact of carotid endarterectomy on medical secondary prevention after a stroke or a transient ischemic attack: results from the Reduction of Atherothrombosis for Continued Health (REACH) registry. Stroke 2006, 37:2880-2885.

4. Puig O, Yuan J, Stepaniants S, Zieba R, Zycband E, Morris M, Coulter S, Yu X, Menke J, Woods J, Chen F, Ramey DR, He X, O'Neill EA, Hailman E, Jhons DG, Hubbard BK, Lum PY, Wright SD, DeSouza MM, Plump A, Reiser W:
Gene expression signature that classifies human atherosclerotic plaque by relative inflammation status. Circ Cardiovasc Genet 2011, 4:595-604.

5. Donners MM, Verluyten MJ, Bouwman FG, Mariman EC, Devreese B, Vanrobaeys F, van Beeumen J, van den Akker LHJM, Daemen MJAP, Heeneman S: Proteomic analysis of differential protein expression in human atherosclerotic plaque progression. J Pathol 2005, 206:39-45.

6. Lepedda AJ, Cigliano A, Cherchi GM, Spirito R, Maggioni M, Carta F, Turrini F, Edelstein C, Scanu AM, Formato M: A proteomic approach to differentiate histologically classified stable and unstable plaques from human carotid arteries. Atherosclerosis 2009, 203:112-118.

7. Olson FJ, Sihlbom C, Davidsson P, Hulthe J, Fagerberg B, Bergström: Consistent differences in protein distribution along the longitudinal axis in symptomatic carotid atherosclerotic plaques. Biochem Biophys Res Commun 2010, 401:574-580.

8. Martinet W, Schrijvers DM, De Meyer DR, Herman AG, Kockx MM: Western array analysis of human atherosclerotic plaques: downregulation of apoptosis-linked gene 2. Cardiovasc Res 2003, 60:259-267.

9. de Kleijn DP, Moll FL, Hellings WE, Ozsarlak-Sozer G, de Bruin P, Doevendans PA, Vink A, Catanzarit LM, Schoneveld AH, Algra A, Daeme MJ, Biessen EA, de Jager W, Zhang H, de Vries JPFalk E, Lim SK, van der Spek PJ, Sze SK, Pasterkamp G: Local atherosclerotic plaques are a source of prognostic biomarkers for adverse cardiovascular events. Arterioscler Thromb Vasc Biol 2010, 30:612-619.

10. Duran MC, Mas S, Martin-Ventura JL, Meilhac O, Michel JB, Gallego-Delgado J, Lazaro A, Tunon J, Egido J, Vivanco F: Proteomic analysis of human vessels: Application to atherosclerotic plaques. Proteomics 2003, 3:973-978.

11. Van Lammeren W, Moll F, Borst GJ, De Kleijn DP, De Vries JP, Pasterkamp G: Atherosclerotic plaque biomarkers: beyond the horizon of the vulnerable plaque. Curr Cardiol Rev 2011, 7:22-27.

12. de la Cuesta F, Barderas MG, Calvo E, Zubiri I, Maroto AS, Darde VM, Martin-Rojas T, Gil-Dones F, Posada-Ayala M, Tejerina T, Lopez JA, Vivanco F, Alvarez-Llama G: Secretome analysis of atherosclerotic and non-atherosclerotic arteries reveals dynamic extracellular remodeling during pathogenesis. J Proteomics 2012, 75:2960-2971.

13. Cooksley-Decasper S, Reiser H, Thommen DS, Biedermann B, Neidhart M, Gawinecka J, Cathomas G, Franzeck FC, Wyss C, Klingenberg R, Nanni P, Roschitzki B, Matter C, Wolint P, Emmert MY, Husmann M, Amann-Vesti B, Maier W, Gay S, Luscher TF, van Eckardstein A, Hof D: Antibody phage display assisted identification of junction plakoglobin as a potential biomarker for atherosclerosis. Plos One 2012, 7:e47985.

14. Cicha I, Wörner A, Urschel K, Beronov K, Goppelt-Struebe M, Verhoevern E, Daniel WG, Garlichs CD: Carotid plaque vulnerability: a positive feedback between hemodynamic and biochemical mechanisms. Stroke 2011, 42:3502-3510.

15. Fisher M: Geometry is destiny for carotid atherosclerotic plaques. Nat Rev Neurol 2012, 8:127-129.

16. Yang C, Canton G, Yuan C, Ferguson M, Hatsukami TS, Tang D: Impact of flow rates in a cardiac cycle on correlations between advanced human carotid plaque progression and mechanical flow shear stress and plaque wall stress. Biomed Eng Online 2011, 19:10-61.

17. Yang C, Canton G, Yuan C, Ferguson M, Hatsukami TS, Tang D: Advanced human carotid plaque progression correlates positively with flow shear stress using follow-up scan data: an in vivo MRI multi-patient 3D FSI study. J Biomech 2010, 43:2530-2538.

18. Fagerberg B, Ryndel M, Kjelldahl J, Akyürek LM, Rosengren L, Karlström L, Bergström G, Olson FJ: Differences in Lesion Severity and Cellular Composition between in vivo Assessed Upstream and Downstream Sides of Human Symptomatic Carotid Atherosclerotic Plaques. J Vasc Res 2010, 47:221-230.

19. Stary HC, Chandler AB, Glagov S, Guyton JR, Insull W Jr, Rosenfeld ME, Schaffer SA, Schwartz CJ, Wagner WD, Wissler RW: A definition of initial, fatty streak, and intermediate lesions of atherosclerosis. A report from the Committee on Vascular Lesions of the Council on Arteriosclerosis, American Heart Association. Circulation 1994, 89:2462-2478.

20. Stary HC: Natural history and histological classification of atherosclerotic lesions: an update. Arterioscler Thromb Vasc Biol 2000, 20:1177-1178.

21. Bendtsen JD, Jensen LJ, Blom N, Von Heijne G, Brunak S: Feature based prediction of non-classical and leaderless protein secretion. Protein Eng Des Sel 2004, 17:349-356.

22. Lilly B, Clark KA, Yoshigi M, Pronovost S, Wu ML, Periasami M, Chi M, Paul RJ, Yet SF, Beckerle MC: Loss of the serum response factor cofactor, cysteine- 
rich protein 1, attenuates neointima formation in the mouse. Arterioscler Thromb Vasc Biol 2010, 30:694-701.

23. van der Loop FT, Gabbiani G, Kohnen G, Ramaekers FC, Van Eys GJ: Differentiation of smooth muscle cells in human blood vessels as defined by smoothelin, a novel marker for the contractile phenotype. Arterioscler Thromb Vasc Biol 1997, 17:665-671.

24. Talusan P, Bedri S, Yang S, Kattapuram T, Silva N, Roughley PJ, Stone JR: Analysis of intimal proteoglycans in atherosclerosis-prone and atherosclerosis-resistant human arteries by mass spectrometry. Mol Cell Proteomics 2005, 4:1350-1357.

25. Ström A, Olin Al, Aspberg A, Hultgårdh-Nilsson A: Fibulin-2 is present in murine vascular lesions and is important for smooth muscle cell migration. Cardiovasc Res 2006, 69:755-763.

26. Sa Q, Hoover-Plow JL: EMILIN2 (Elastin microfibril interface located protein), potential modifier of thrombosis. Thromb J 2011, 9:9.

27. Smadja DM, D'Audigier C, Bièche I, Evrard S, Mauge L, Dias V-J, Labreuche J, Laurendeau I, Marsac B, Dizier B, Wagner-Ballon O, Boisson-Vidal C, Morandi V, Duong-Van- HJ-P, Bruneval P, Dignat-George F, Emmerich J, Gaussem P: Thrombospondin-1 is a plasmatic marker of peripheral arterial disease that modulates endothelial progenitor cell angiogenic properties. Arterioscler Thromb Vasc Biol 2011, 3:551-559.

28. Gasparri C, Curcio A, Torella D, Gaspari M, Celi V, Salituri F, Boncompagni D, Torella M, Gulletta E, Cuda G, Indolfi C: Proteomics reveals high levels of vitamin D binding protein in myocardial infarction. Front Biosci 2010, 2:796-804.

29. Rocchiccioli S, Andreassi MG, Cecchettini A, Carpeggiani C, L' Abbate A, Citti L: Correlation between vitamin $D$ binding protein expression and angiographic-proven coronary artery disease. Coron Artery Dis 2012, 23:426-431.

30. Slevin M, Elasbali AB, Miguel Turu M, Krupinski J, Badimon L, Gaffney J: Identification of differential protein expression associated with development of unstable human carotid plaques. Am J Pathol 2006, 168:1004-1021.

31. Gomez D, Owens GK: Smooth muscle cell phenotypic switching in atherosclerosis. Cardiovasc Res 2012, 95:156-164.

32. Rocchiccioli S, Ucciferri N, Comelli L, Trivella MG, Citti L, Cecchettini A: Proteomics changes in adhesion molecules: a driving force for vascular smooth muscle cell phenotypic switch. Mol Biosyst 2012, 4:1052-1059.

33. Formolo CA, Williams R, Gordish-Dressman H, MacDonald TJ, Lee NH, Hathout Y: Secretome signature of invasive glioblastoma multiforme. J Proteome Res 2011, 10:3149-3159.

doi:10.1186/1479-5876-11-260

Cite this article as: Rocchiccioli et al.: Secreted proteins from carotid endarterectomy: an untargeted approach to disclose molecular clues of plaque progression. Journal of Translational Medicine 2013 11:260.

\section{Submit your next manuscript to BioMed Central and take full advantage of:}

- Convenient online submission

- Thorough peer review

- No space constraints or color figure charges

- Immediate publication on acceptance

- Inclusion in PubMed, CAS, Scopus and Google Scholar

- Research which is freely available for redistribution 